www4.fsanet.com.br/revista

Rev. FSA, Teresina, v. 18, n. 02, art. 13, p. 241-256, fev. 2021

ISSN Impresso: 1806-6356 ISSN Eletrônico: 2317-2983 http://dx.doi.org/10.12819/2021.18.02.13

\title{
A Discursividade em Rio Turuna: Uma Análise de Sujeitos e Sentidos da Identidade Goiano- Tocantinense
}

\section{The Discursivity in Rio Turuna: An Analysis of Subjects and Meanings of the Goiano- Tocantinense Identity}

Thiago Barbosa Soares

Doutor em Linguística pela Universidade Federal de São Carlos Professor da Universidade Federal do Tocantins no campus de Porto Nacional E-mail: thiago.soares@mail.uft.edu.br

Cinara Teodoro Maia

Mestranda em Linguística pela Universidade Federal do Tocantins Licenciada em Letras pela Universidade Federal do Tocantins E-mail: thiago.soares@mail.uft.edu.br

Endereço: Thiago Barbosa Soares

Universidade Federal de São Carlos. Rod. Washington Luiz, s/n, São Carlos - SP, 13565-905. Brasil.

Endereço: Cinara Teodoro Maia

Universidade Federal do Tocantins, Avenida Paragua,i s/n Setor - Bairro da Cimba, Araguaína - TO, 77824-838. Brasil.
Editor-Chefe: Dr. Tonny Kerley de Alencar Rodrigues

Artigo recebido em 08/01/2021. Última versão recebida em 19/01/2021. Aprovado em 20/01/2021.

Avaliado pelo sistema Triple Review: a) Desk Review pelo Editor-Chefe; e b) Double Blind Review (avaliação cega por dois avaliadores da área).

Revisão: Gramatical, Normativa e de Formatação 


\title{
RESUMO
}

O presente estudo abre-se para as percepções inerentes à Análise do Discurso, da linha francesa, com o intuito de descrever a língua agindo como atividade social, por meio da interação cultural, ideológica, no processo de alteridade, bem como os aspectos situacionais que interferem nas diversas práticas sociais, como neste caso, na literatura regional de Eli Brasiliense, Rio Turuna. Seguindo a premissa de que sujeito e sentido constituem-se ao mesmo tempo, bem como a de que esse sujeito compreende as relações sociais, somente pela língua (ORLANDI, 1999), esta análise traz à tona a subjetividade do sujeito do norte goiano, atual Tocantins, apresentada por meio da obra regionalista, Rio Turuna. Assim, tendo em vista a compreensão do processo de formação discursiva na obra, bem como das relações de sentidos, de subjetividade que nela se formam, faz-se aqui uma busca na base teórica da Análise do Discurso, em autores como Pêcheux, Althusser, Orlandi, Foucault, entre outros. Ao final, apresenta-se uma análise de Rio Turuna, como condições para a identificação das instâncias ideológicas que fazem emergir a identidade goiano-tocantinense.

Palavras-Chave: Rio Turuna. Eli Brasiliense. Análise do Discurso.

\begin{abstract}
The present study opens up to the perceptions inherent to Discourse Analysis, of the French line, in order to describe the language acting as a social activity, through cultural, ideological interaction, in the process of alterity, as well as the situational aspects that interfere in different social practices, as in this case, in the regional literature of Eli Brasiliense, Rio Turuna. Following the premise that subject and meaning are constituted at the same time, as well as that this subject understands social relationships, only through language (ORLANDI, 1999), this analysis brings up the subjectivity of the subject from the north of Goiás, current Tocantins, presented through the regionalist work, Rio Turuna. Thus, with a view to understanding the process of discursive formation in the work, as well as the relations of meanings, subjectivity that are formed in it, a search is made here on the theoretical basis of Discourse Analysis, in authors such as Pêcheux, Althusser, Orlandi, Foucault, among others. At the end, an analysis of Rio Turuna is presented, as conditions for the identification of the ideological instances that cause the identity of Goiás-Tocantins to emerge.
\end{abstract}

Key words: Rio Turuna. Eli Brasiliense. Discourse Analysis. 


\section{INTRODUÇÃO}

O presente estudo abre-se para as percepções inerentes à Análise do Discurso, da linha francesa, com o intuito de descrever a língua agindo como atividade social, por meio da interação cultural, ideológica, no processo de alteridade, bem como os aspectos situacionais que interferem nas diversas práticas sociais, como neste caso, na literatura regional de Eli Brasiliense, Rio Turuna.

Em contraposição à abordagem da língua como instrumento de comunicação, em que esta é concebida como um código por onde um emissor comunica a um receptor determinadas mensagens, sem dificuldades, Marcuschi (2008, p. 139) anuncia outras possibilidades ao simplismo da operação que "apresenta de um lado o texto e do outro os indivíduos que, em condições específicas, podem compreender conteúdos e sentidos sem maiores problemas”. Nessa perspectiva, ancorado a essas proposições, a língua não é transparente, tampouco desvinculada da história, ou seja, do seu uso social.

Seguindo a premissa de que sujeito e sentido constituem-se ao mesmo tempo, bem como a de que esse sujeito compreende as relações sociais, somente pela língua (ORLANDI, 1999), esta análise traz à tona a subjetividade do sujeito do norte goiano, atual Tocantins, apresentada por meio da obra regionalista, Rio Turuna.

É indiscutível nos meios acadêmicos a potencialidade interpretativa, contida nas obras literárias. Essa potencialidade está na compreensão do texto literário como um importante testemunho da realidade social e cultural de um povo, em determinado tempo e lugar, sendo o autor intérprete de uma realidade vivenciada.

Eli Brasiliense, escritor radicado em Goiânia na década de 1950, nasceu em Porto Nacional (TO) e se consagrou como um dos maiores escritores do regionalismo modernista que inaugurou autores como Graciliano Ramos, Bernardo Elis, entre outros (ALMEIDA, 1985). A obra de Eli Brasiliense Rio Turuna (1964), Uma sombra do fundo do rio (1977) e Pium (1984) é ambientada nas ribeiras do Tocantins de meados do século XX e é rico nos detalhes da vida do homem do sertão tocantinense.

Por esta razão, com o intuito de compreender a vida e formação da identidade ribeirinha tocantinense, em época anterior à criação do Estado do Tocantins, em 1988, elegese para esse estudo a obra "Rio Turuna" publicada em 1964. A obra e seu autor se inserem no campo da literatura regional, trazendo elementos da representação simbólica de importantes aspectos da vida social, econômica e cultural. Estes, por sua vez, possibilitam a compreensão dos elementos constitutivos de respectiva cultura e identidade do homem tocantinense, que se 
constrói por meio das formações discursivas e apresenta-se nas práticas discursivas cotidianas.

A trama apresentada por Eli Brasiliense hoje possui densidade histórica, uma vez que resgata aspectos culturais e identitários de um povo, que até então jamais sonhara participante da memória viva de uma região geodesicamente centralizada, cujo futuro próximo traria uma divisão espacial geográfica, embora muito antes planejada e esperada por seus antepassados, de mudanças preponderantemente transformadoras e irrevogavelmente definitivas.

A preciosidade da obra eliana reside na possibilidade de voltar no tempo e apreciar, por meio da citada literatura, a subjetivação do sujeito tocantinense em detrimento às transformações políticas ambientado às margens do rio que, futuramente, cederia seu nome ao novo Estado, gestor desse território (LEITE, 1983).

Assim, tendo em vista a compreensão do processo de formação discursiva na obra, bem como das relações de sentidos, de subjetividade que se formam, faz-se aqui uma busca na base teórica da Análise do Discurso, em autores como Pêcheux, Althusser, Orlandi, Foucault, entre outros. Ao final, apresenta-se uma análise da literatura utilizada, como pano de fundo para a identificação das instâncias ideológicas que fazem emergir a identidade goianotocantinense.

\section{REFERENCIAL TEÓRICO}

As palavras, enquanto práticas discursivas, assim como a formação discursiva de uma comunidade, desenham o seu perfil identitário, fazem emergir a subjetividade coletiva que, por sua vez, dá vida à cultura e demais traços sociais de referida população.

Para a Análise do Discurso, a linguagem é a articulação imprescindível entre o homem e a realidade natural e social. Essa interferência possibilita permanências, deslocamentos e transformações do sujeito e da realidade à sua volta. Orlandi $(1999$, p. 15) ressalta que "o trabalho simbólico do discurso está na base da existência humana”.

\footnotetext{
Levando em conta o homem na sua história, considera os processos e as condições de produção da linguagem, pela análise da relação estabelecida pela língua com os sujeitos que a falam e as situações em que se produz o dizer. Desse modo, para encontrar as regularidades da linguagem em sua produção, deve-se relacionar a linguagem à sua exterioridade. (ORLANDI, 1999, p. 16).
}

A linguagem faz sentido, torna-se elemento de significação para comunidades sociais e culturais quando imbricada em sua história, quando contextualizada, como parte natural de uma formação discursiva específica. Nessa perspectiva, exercer a prática discursiva significa 
"falar segundo determinadas regras e expor as relações que se dão dentro de um discurso" (OLIVEIRA, 2013, p. 139).

Vale reportar, também, às anotações de Foucault (2009) quanto à noção de formação discursiva, segundo a qual é definida por regras anônimas e históricas, espacial e temporalmente determinadas, que para cada período e dimensão social, econômica, geográfica ou linguística, definiram as condições de exercício da função enunciativa. (FOUCAULT, 2009, p. 133).

Voltando às práticas discursivas, observa-se que cotidiana e mecanicamente sujeitos se valem de determinadas formações discursivas, acreditando usar de total liberdade de expressão ao propagar ideias e pensamentos. Mal sabem que a linguagem, seja ela coloquial ou em norma padrão, mesmo aquela expressa no dia-a-dia, no processo de alteridade, já chega carregada de sentidos.

Mesmo numa análise superficial, não discursiva, é sabido que o que ora é dito não parte de um saber imediatamente descoberto, ou que "reinventa-se a roda" a cada ato de fala, ou ainda que o sujeito seja autor do próprio dizer. Segundo Orlandi (1999, p. 33), esse esquecimento ideológico "é da instância do inconsciente", resultado de como o indivíduo é afetado ideologicamente e retoma o sonho adâmico, "o de estar na inicial absoluta da linguagem". Por isso pode ser dito que se tem a ilusão de ser a origem do que se diz, quando na verdade o que se nota é o retorno a sentidos preexistentes. Dessa forma, do ponto de vista discursivo, ocorre a todo o momento um atravessamento entre língua e objeto de uma memória discursiva, que por sua vez determina as práticas discursivas. Em outras palavras, o dizer do sujeito é determinado sempre por outros dizeres, ou "todo discurso é determinado pelo interdiscurso". (GUERRA, 2003, p. 4).

Sujeitos estão ligados ao saber discursivo, que embora não possa ser apreendido, apresenta-se por meio do inconsciente e das ideologias que os interpelam, recrutam e envolvem. É por meio do interdiscurso que as ideologias falam e atravessam o discurso. Por esta razão, concorda-se com a afirmativa: "alguma coisa fala antes do sujeito, em outro lugar, independentemente" (SANTOS, 2013, p.219). Por isso, torna-se premissa à Análise do Discurso. Orlandi (1999, p. 25), vai além ao afirmar que "o saber discursivo torna possível todo dizer e retorna sob a forma do pré-construído, do já-dito que está na base do dizível, sustentando cada tomada da palavra".

Fato incontestável é que a língua, o sujeito e a história não existem um sem o outro. O sujeito é diretamente afetado pela história, e a psicanálise aponta para um deslocamento de sentidos quanto à noção de homem, enquanto indivíduo, para a de homem como sujeito. É 
desta concepção que Orlandi (1999, p. 38) reitera a contribuição da psicanálise para a noção de sujeito, porque segunda ela, o sujeito perde seu lugar empírico para tomar uma posição discursiva. E é dessa posição que se pode conceber um indivíduo interpelado em sujeito pela ideologia. Assim, ao construir a dinâmica da alteridade, o sujeito produz evidências, "o colocando em uma relação imaginária com suas condições materiais de existência" (ORLANDI, 1999, p. 44).

Althusser (1970, p. 93) vai adiante ao afirmar que "só existe ideologia pelo sujeito e para sujeitos". O autor afiança que a ideologia interpela sujeito, tornando-o sempre, necessariamente, "sujeito a"; e mais ainda que toda ideologia tem por função (que a define) “constituir os indivíduos concretos em sujeitos." (ALTHUSSER, 1970, p. 94). Sobre o tema, Pêcheux (1995) vem alertar para o fato de que a interpelação age retroativamente, fato que faz de todo indivíduo um "sempre-já sujeito".

A ideologia já está lá, sempre existiu. Autores como Pêcheux e Althusser, reportando a afirmativa Freudiana "o inconsciente é eterno", anunciam que a ideologia é eterna. Eterna, não quanto à temporalidade, mas na onipresença, no já dito, nos atravessamentos do interdiscurso.

O já-dito sobrevive no interdiscurso e segue sustentando as possibilidades de expressão do dizer em suas várias nuances. Por meio daquilo que um dia foi dito, em determinada formação discursiva, em algum tempo e lugar, pode se compreender a prática discursiva atual, o funcionamento do discurso e sua relação com os sujeitos e com a ideologia, explica Orlandi (1999, p. 31), afirmando que "O interdiscurso disponibiliza dizeres que afeta o modo como o sujeito significa em uma situação discursiva dada”.

É lá no curso da história que mora a ideologia. Ali o saber discursivo se criou e se perpetuou. No domínio da historicidade o saber discursivo foi se formando e, ao longo da história, produzindo dizeres. A materialidade da linguagem considera os aspectos linguístico e histórico, como "indissociáveis no processo de produção do sujeito do discurso e dos sentidos que o significam, o que possibilita afirmar que o sujeito é um lugar de significação historicamente constituído" (GUERRA, 2003, p. 10).

[...] empreender a análise do discurso significa tentar entender e explicar como se constrói o sentido de um texto e como esse texto se articula com a história e a sociedade que o produziu. $\mathrm{O}$ discurso é um objeto, ao mesmo tempo, lingüístico e histórico; entendê-lo requer a análise desses dois elementos simultaneamente. (GREGOLIN, 1995, p. 13). 
Diversos autores da Análise do Discurso da linha francesa, como Pêcheux e Foucault, bem como seus seguidores no Brasil, cuja representação pode ser concedida tranquilamente a Orlandi, vêm afirmando que a história se materializa, porém, não é transparente ao próprio homem que a constitui. Assim, tendo em vista envolver língua e história, com foco na produção de sentidos, concebem o materialismo linguístico-histórico como a fórmula ideal para tal fim. (ORLANDI, 1999, p. 19)

A materialidade linguística é imprescindível para que a ideologia aconteça nos lugares em que funciona e produz sentidos sob determinadas condições de produção. Assim ela cria "as condições para inscrever, de modo concreto, a história na ordem do discurso e o discurso no campo da práxis". (SANTOS, 2013, p. 213)

Ainda sobre a ideologia vale insistir que toda prática discursiva não ocorre sem o sujeito, e ainda confirmar a tese de que não existe sujeito sem a ideologia agindo ininterruptamente em sua performance cotidiana. E de todas as afirmativas, quanto ao tema, a mais importante à linguística é a de que a língua somente faz sentido por meio da ideologia, reportando aqui a Orlandi (1999).

\section{RESULTADOS E DISCUSSÕES}

\subsection{Uma análise de Rio Turuna}

A literatura representa bem mais que narrativas de histórias sobre características prédefinidas ou enquadradas em períodos histórico-literários pela academia. Desde Homero, a literatura desempenha seu papel imprescindível para a formação social, cultural, linguística, filosófica e histórica dos povos. Soares (2018, p. 82) esclarece que em textos literários “os diálogos com as mentalidades nem sempre são evidentes, porém não deixam de ocorrer, dada a própria condição segundo a qual a literatura se encontra, de uso da língua”.

A literatura é um fenômeno da civilização pelo qual todo e qualquer escritor se serve para expressar pensamentos e sentimentos, e para esse fim se vale de entrelaçamentos de diversos fatores sociais do contexto ao qual se refere ou realiza recortes temporais e espaciais (MAYA, 2003).

Romances literários, em tramas fictícias ou não, apresentam personagens realizando em seu cotidiano práticas discursivas. Nessa perspectiva, percebe-se que a produção de sentido independe da literalidade, uma vez que esta constitui e é constituída por determinadas condições de produção. Segundo abordagem Foucaultiana, "discursos não preexistem às 
cenas enunciativas: eles a constituem permanentemente, e na mesma medida são constituídos por elas" (FOUCAULT, 2009, p. 139).

Desse ponto de vista, Eli Brasiliense traz em Rio Turuna uma temática contemporânea ao modernismo literário, porém opta por enquadrar sua obra no movimento então definido como "Neorrealismo", cujo viés evoca a "problemática humana".

Adeptos da mesma corrente literária, muitos romancistas nordestinos como José Lins do Rego, Jorge Amado, Graciliano Ramos, entre tantos outros reconhecidos escritores nacionais, colocaram em destaque, por todo o Brasil, uma literatura de cunho regionalista, e provocaram o ressurgimento de nuances sócio-políticas e econômico-sociais nas tramas (ALVES, 1985, p. 34).

O então notável romancista Eli Brasiliense apresenta em sua obra um mundo ficcional preso ao universo real, realizando uma mistura instigante ao mostrar situações e nomes locais verídicos, associados a um alto valor estético e humano, segundo relato da autora Nely Alves, em "Presença Literária de Ely Brasiliense”, sua obra publicada em 1985.

O autor, conterrâneo dos personagens da trama ora analisada, talvez por esta razão, traz uma história carregada de sentimentalismo pela região notadamente isolada do resto do País, pela localização centralizada e distante dos grandes centros urbanos. O universo ficcional é posto pela onipresença de um rio personagem, o Rio Tocantins, testemunha ocular da trama que em suas ribeiras se passa. Alves (1985, p. 35) ressalta os múltiplos elementos que despontam na ficção, como "língua, linguagem, personagens reais e criadas, quietude e miséria do sertão, usos e costumes dos seus habitantes."

Para esta análise, adota-se como procedimento a interpretação de enunciados na trama, a fim de compreender o atravessamento do intradiscurso - horizontal - pelo interdiscurso vertical (COURTINE, 2009). Mantém-se o foco nos enunciados que, através da discursividade e historicidade trabalha a materialidade histórica da linguagem. De acordo com Orlandi (1999, p. 66), vê-se no texto "os conteúdos da história”. Estes "são tomados como discursos, em cuja materialidade está inscrita a relação com a exterioridade". Assim os enunciados evidenciam a construção da prática em respectiva formação discursiva. Reportando ao conceito do "já-dito" que é parte da memória discursiva, e que por sua vez fazse presente em toda prática discursiva, por meio do interdiscurso. Soares vem falar de "uma memória que não se cala, de forma que é recorrentemente textualizada, produzindo efeitos de sentidos, entre um deles, o de literalidade" (SOARES, 2016, p. 1087).

A trama eliense apresenta uma história contextualizada na década de 1940. Esse período é carregado historicamente pela herança do Brasil colônia, pelas guerras de 
conquistas territoriais e pela forte presença das forças repressoras do Estado. Ressaltando as conquistas por territórios, as demarcações fronteiriças como pano de fundo para a disputa pelo poder.

Os ataques diversos, guerras e tomadas ocorreram pelo interior de todo País, deixando as marcas de devastações na região deste município que um dia fora "Bom Jesus do Pontal", posteriormente recebera a alcunha de arraial de "Porto Real", passando a "Porto Imperial", por ocasião da gestão monárquica no País, como relata Godinho (1988), em seu livro "História de Porto Nacional". O autor informa que o julgado de "Porto Real" passou à categoria de vila, com a denominação de "Porto Imperial", por meio da Lei Provincial, de 14 de novembro de 1831, instalada em 24 de abril de 1832 (Godinho, 1988, p. 29). O autor segue relatando que alguns dos principais motivos da promoção de Porto Real a patamar de vila foram "o declínio progressivo da mineração nos aglomerados vizinhos, o desaparecimento de Pontal e o incremento da navegação do Tocantins, proporcionadora de ativo comércio com a Praça de Belém do Pará".

Assim, história e ficção se misturam em "Rio Turuna", espaço literário onde o autor conta sua cultura, crenças e memórias, entre os "causos" dos personagens também narradores, testemunhas e coadjuvantes da trama.

\begin{abstract}
Ao alto da barranca de Pôrto Real ficava um possante cruzeiro de aroeira, comemorativo do Centenário da independência. O rio parecia respeitar-lhe o direito de estar ali. [...] o canhão deixado por um alferes não tivera nenhuma utilidade para reconstruir os bagaços do Pontal, já transformado em viveiro de assombrações, de ouro encantado, de histórias que afugentavam os sertanejos crendeiros. [...] o arrasamento da vila de Bom Jesus do Pontal pelos índios enfurecidos e vingativos. Dessa matança haviam sobrado poucas pessoas, apenas para servir de semente para a formação de Pôrto Nacional. (BRASILIENSE, 1964, p. 17).
\end{abstract}

Vale aqui buscar em Orlandi (1999, p. 54) o respaldo teórico para compreender o agir da memória discursiva, no interdiscurso, quando afirma que "O interdiscurso - memória discursiva- sustenta o dizer em uma estratificação de formulações já feitas, mas esquecidas e que vão construindo uma história de sentidos".

A sociedade representada na trama traz, em sua formação subjetiva, resquícios das organizações hierárquicas do sistema de governos de monarquias e seus impérios. Assim, a sociedade brasileira, herdeira de referida organização, consequentemente, segue observando tais padrões.

Apontamentos históricos brasileiros, relatam que após a Independência do Brasil, em 1831, foi criada, pelo Pe. Diogo Antônio Feijó, enquanto Ministro da Justiça, a Guarda Nacional - uma companhia paramilitar cujas patentes eram semelhantes às dos militares da 
ativa e eram oferecidas às mais importantes lideranças políticas em várias partes do país, escolhidas entre os municípios, como parte de um "artifício" que os transformava em oficiais da Guarda Nacional, "agentes” do poder central, para garantirem apoio ao Governo. Tal poder concedido era acompanhado de privilégios a lideranças que o exerciam de modo unilateral, numa subversão à democracia, no contexto das comunidades em que viviam sempre com o apoio oficial. Assim, surgiu no Brasil o regime do "Coronelismo" (RAMOS, 1989).

Em Porto Nacional, a realidade da "familiocracia", do "coronelismo", bem como da constituição governamental oligárquica ocorria tal qual no contexto nacional, pois se encontravam nessa região, fortemente, estas ordens hierárquicas associadas. Esse importante centro econômico, na Primeira República, viveu sob as ordens do chamado "pacto coronelístico". (PALACIN, 1990).

Muitas dessas patentes eram compradas, esclarece Rodrigues (2006, p. 41-43), de modo que "a magia militar, política, social e econômica que eles exerciam sobre os demais cidadãos comuns era angustiante e ao mesmo tempo protetora e fraternal." Entre as patentes de Coronel, Major, Capitão, Tenente, Tenente-Coronel e todos os demais postos em que figuravam honrarias militares e ostentação de luxo pelos prestigiosos chefes políticos do interior, ali se encontrava a alta sociedade portuense. No topo da pirâmide social portuense, estavam as tradicionais famílias que, de geração para geração, se cristalizaram no poder pela acumulação de terras e de ouro.

Em específico, no recorte aqui analisado, há uma utilização exacerbada de patentes e cargos, como forma de demarcação do poder. O poder repressivo e abusivo era aplicado na região segundo convenções sociais, uma vez que o distribuíam, de forma aleatória, entre os cidadãos locais, como se vê abaixo:

\footnotetext{
Aqui no Pôrto, afirmava ele - quem despachava bote era coronel, quem soltava batelão era major, mas aquêle que não tinha canoa, a não ser fazendeiro grande do seco, não chegava a vintém. Era peixe miúdo [...] Isto era nos bons tempos da Guarda Nacional quanto às altas patentes eram compradas pelos vaidosos mandachuvas das cidades do interior. Às margens do Tocantins havia muitos capitães, majores, tenentes-coronéis e coronéis que não sabiam como manejar uma espada, nem fazer continência direito, e cujos filhos eram logo chamados de capitãozinho. A maioria dos postos eram dados de acordo com as embarcações ou fazendas que possuíam. (BRASILIENSE, 1964, p. 81).
}

É sobre essa memória, sobre a qual não se tem o controle, que a consciência se constrói, no já-dito do interdiscurso, causando a impressão que o tempo todo, o sujeito sabe 
do que está falando. Quanto a esse fenômeno, Orlandi (1999, p. 54) assegura que "nasce aí, a ilusão de que somos a origem do que dizemos".

Todo sujeito, ao praticar o ato de fala, cotidianamente, reforça e perpetua as relações de poder. O lugar de onde fala, ou seja, a posição "sociofuncional" que ocupa em sua comunidade permite ao sujeito falar de determinada forma e com propriedade tal, que sua fala denuncia uma ideologia que o recrutou e que, consequentemente, o faz reproduzir e perpetuar ideologias e hierarquias (ORLANDI, 1999, p. 39).

A história local é materializada no perfil identitário dos personagens citados. A herança de caráter e atitudes, sob a égide de lembranças de guerras historicamente travadas e imbricadas na memória discursiva, é perceptível na descrição do rio Tocantins, que inspira o título da obra Rio Turuna. Trata-se de um topônimo indígena que significa "poderoso", "forte", "bravo", em reverência ao rio cuja tamanha importância o torna "testemunha" de todo o relato, inspirando o povo portuense quanto a características atitudinais levam os mesmos adjetivos que definem o rio personagem. Assim o autor "amorosamente" refere-se ao Rio

\title{
Turuna:
}

\begin{abstract}
Este pedaço do rio é todo de mansidão mentirosa, menino! O Tocantins é rio macho, rio turuna meio amalucado. Mata caboclo forte só pra dizer que tem mais força. [...]. O homem da margem do Tocantins havia de ser de aço, cabra capaz de matar onça canguçu com zagaia, de enfrentar sucuri grande como Manoel Bacaba, de retalhar desaforado no facão, que nem seu vizinho Miguel. Era preciso desafiar o rio, montar-lhe no lombo e amansá-lo, como se dominava um poldro chucro. Do contrário seria desmoralizado e jogado para os gerais, onde permaneceria sempre como um extraviado, um cisco atirado pelas enchentes. Transformar-se-ia num catador de abóboras no monturo dos boqueirões [...]Todos homens de coragem poderiam cavalgar o Tocantins, que não era propriedade de ninguém, era estrada livre até o mar. Isto mesmo, Simão! O rio turuna era um poldro brabo, de lombo liso, que chotava nos travessões e disparava nas cachoeiras, bufando e pinoteando, sem freio que o aguentasse. Chicoteado pelas luvas grossas, subia o barranco de uma noite para o dia, pegava gente de surprêsa, levava casas e desmanchava roças. Desmoronava ribanceiras em corrida louca, a escavar a terra fôfa, onde esgaravatava as raízes mais fundas. Escoceiava as árvores de encontro às perambeiras, espatifando-as. Depois chupava bastante ar pela bôca dos funis, para bufar com estrondo no estouro dos rebojos. [...]. O homem forte, nascido e criado ali, mesmo de aparência franzina, navegava o rio brincando, porque se acostumara com sua brabeza desde menino. Alguns visitantes da cidade, gente mole criada no sêco, acostumada com aguinha de latas, não tinha coragem de chegar no barranco, para olhar a fundura azul do rio (BRASILIENSE, 1964, p. 36).
\end{abstract}

Evidenciam-se na obra retratada as relações de poder que se travavam no cotidiano. A Análise do Discurso de linha francesa faz uso da abordagem Althusseriana, a fim de compreender estratégias de dominação utilizadas pelo Estado para manter a hegemonia do 
poder. O autor aponta e distingue os aparelhos do Estado em Aparelho Ideológico de Estado AIE e aparelho repressivo de estado (ARE), ressaltando que "o aparelho repressivo do estado funciona pela violência, enquanto os aparelhos ideológicos de estado funcionam pela ideologia." (ALTHUSSER, 1970, p. 46). Em Rio Turuna há diversas passagens nas quais se apresentam os aparelhos tanto ideológicos quanto repressivos do Estado em pleno funcionamento, nas práticas discursivas, como o exposto a seguir:

O major Antônio Pinheiro tinha sua meia dúzia de armas também. O delegado de Polícia era seu afilhado, além disso, a força moral do velho era respeitada em toda a cidade. Intendente Municipal por duas vezes agora era presidente da Irmandade do Santíssimo e tesoureiro do Cofre das Almas (BRASILIENSE,1964, p. 63).

Numa sociedade sob o julgo coronelista, vê-se na prática o discurso agindo nas relações de forças, tomado pelas condições de produção vigentes, e perpetuando-se pelo poder constituído e institucionalizado. As patentes oficiais e não oficiais, usurpadas pelos sujeitos, caracterizam o próprio poder repressor do Estado, em ação, na sociedade. Por sua vez o "coronelismo", como vertente desse poder repressor, emerge sob um viés ideológico, mostrando-se também a serviço da manutenção do poder do Estado, desta feita por via indireta.

Veem-se na trama, relações sustentadas a partir das infindáveis possibilidades hierárquicas do poder, que se estabelecem no convívio social, e emergem insistentemente, por meio das práticas discursivas. Sobre o assunto Althusser (1970, p. 62) aponta que "Todos os aparelhos ideológicos de Estado, sejam eles quais forem, concorrem para um mesmo resultado: a reprodução das relações de produção, isto é, das relações de exploração capitalistas" (ALTHUSSER, 1970, p. 62).

Rio Turuna apresenta personagens divididos entre a bravura do povo e a covardia do coronelismo, entre a justiça repressora institucionalizada e a justiça aplicada pelas próprias mãos, sob o lema do "dente por dente, olho por olho", pelas mãos dos jagunços que, por sua vez, também eram mandados dos coronéis, como vemos em alguns excertos abaixo:

\footnotetext{
Liduíno, porém era bem diferente. Matava mesmo, de faca ou de tiro, e não contava suas mortes. Agia manhosamente que nem doença traiçoeira (BRASILIENSE, 1964, p. 25).

...tição amaldiçoado, cabra mau dos infernos, cuja maldade era capaz de secar a água do rio, de tocar fogo no mundo, de matar uma plantação com mau-olhado! (BRASILIENSE,1964, p. 28).
} 
...quantas marcas já possuía na coronha daquela arma? Ninguém o sabia, nem era capaz de calcular. De bicho do mato? Não, que esses êle não contava, mas de gente batizada. Por qualquer conto de réis tirava uma vida. (BRASILIENSE, 1964, p. 29).

Era pena não poder lutar com o jagunço frente a frente, no tiro ou na faca, para que todos soubessem que êle não era mais homem do que ninguém. Era apenas mau, alugando sua ruindade a qualquer endinheirado. (BRASILIENSE, 1964, p. 38)

Chegara a Porto Nacional um juiz de direito, esse homem deixou fama naquelas paragens. Era muito agarrado com aos códigos, e não dava assunto aos peditórios ou ameaças de gente rica. Começara a consertar tudo aquilo que estava errado, desengavetando processos, a examinar inventários antigos, onde havia menores pelo meio. Os escrivães andavam numa correria para normalizar a situação de seus cartórios. Logo o juiz ficara marcado porque mexera em casa de marimbondos. (BRASILIENSE, 1964, p. 82)

Justiça e poder em Rio Turuna são manifestados de vários lugares e níveis sociais. Em seus desdobramentos encontram-se aí a justiça e o poder ora institucionalizados ora oriundos do povo; por sua vez o discurso está sempre a serviço do poder, seja ele institucionalizado ou não, não importando sua origem. Assim sendo, Foucault afiança que "O poder não é fonte nem origem do discurso". O poder é alguma coisa que opera através do discurso, já que o próprio discurso é um elemento em um dispositivo estratégico de relações de poder. (FOUCAULT, 2003, p. 252).

Como já mencionado, a Análise do Discurso, segundo Michel Pêcheux (1975), alerta para aquilo que pode ser chamado de "esquecimentos", enumerando-os em 2, sendo o esquecimento número 1 o esquecimento ideológico, em nível inconsciente, segundo o qual o sujeito tem a ilusão de que é origem de tudo aquilo que diz, isto é, que seria o primeiro a dizer determinadas palavras que significariam exatamente o que ele quis dizer, quando na verdade retoma sentidos pré-existentes. Pêcheux (1975) afirma ainda que o sujeito faz uso também do esquecimento número 2 ao acreditar que há uma ligação direta entre o pensamento, a linguagem de modo que tudo o que se diz somente pode ser dito desta forma e não de outra. Assim entra-se no looping da ideologia, retomando-a constantemente e perpetuando-a, segundo a memória discursiva do já-dito.

Esquecimentos número 1 e 2 fazem-se presentes na prática discursiva apresentada na trama eliense, como ratificam os excertos acima. Cada sujeito apropria-se da autoridade que lhe é atribuída pelo próprio sistema que o assujeita, e segundo tal autoridade, age imbuído do poder que o "autoriza" enquanto coronel, major, barqueiro, delegado ou mesmo jagunço, em específica condição de produção discursiva. 
Inconscientemente ou não, sujeitos na prática discursiva cotidiana, reproduzem ideologias e colaboram para a perpetuação das relações de poder inerentes, sobretudo aos sistemas de produção capitalista.

\section{CONSIDERAÇÕES FINAIS}

O mundo vive a era da tecnologia digital e da acelerada comunicação virtual. Discussões sob temáticas diversas são postas pelos vários canais e redes sociais às também mais diversas comunidades e grupos de internautas. Porém o que se vê são discussões fúteis e argumentos rasos sobre o leque variadíssimo de assuntos. Não se pode negar a capacidade criativa de sujeitos que se atrevem a participar dos bate-papos propostos, no entanto percebese, talvez pela rapidez e excesso de comunicação, o fenômeno da superficialidade analítica em meio aos debates. A Análise do Discurso, em contramão a tudo aquilo que se percebe somente na superficialidade, vem convidando ao mergulho nas profundezas das entrelinhas do não dito e do já-dito.

A linguagem, por meio do discurso, está sempre trazendo de volta os já ditos, trata-se da memória sendo revisitada e se fazendo valer. Orlandi explica que a comunicação transita entre processos parafrásticos e polissêmicos. O parafrástico é o dizível por meio da memória, segundo o qual se retorna ao que um dia foi dito, aos espaços do dizer. A polissemia, por sua vez é a ruptura com os processos de significação. (ORLANDI, 1999, p. 36).

O discurso é, pois, o resultado do trânsito da linguagem entre esses dois processos, de modo que todas as vezes que falamos, mexemos nas redes de sentidos, porém falamos com palavras que já foram ditas. Nessa dialética, então, entre o dito e a se dizer, os sentidos se movimentam, reforça Orlandi (1999, p. 36).

A proposta desse estudo foi analisar o discurso ideológico, por meio da trama criada há quase um século, em cujos discursos abordados apresentam-se traços da sociedade atual. Ou seja, uma trama embora quase secular, atualíssima quanto à formação discursiva.

A sociedade fictícia tão bem representada por Eli Brasiliense remete a uma comunidade habitante do norte goiano, que, na época estabelecida pelo recorte literário, vivia uma forte dualidade identitária, tanto quanto por sua localização físico-geográfica quanto pela luta separatista.

As comunidades que se estabeleceram nesta região centralizada do Brasil, mais especificamente no norte de Goiás, sempre viveam a questão separatista que teve como causa 
motriz a sua localização distante dos grandes centros urbanos comerciais, que as deixavam em desvantagem em ralação às demais regiões do País.

Resquícios de uma sociedade de quase um século atrás teimam em se manifestar na sociedade atual por meio de uma memória que fala ininterruptamente. A Porto Nacional de hoje ainda mantém nos topônimos de instituições públicas escolares e também de algumas ruas do centro histórico, os nomes dos marechais e coronéis. A sociedade tocantinense, tal qual a brasileira em geral, mantém o discurso contraditório entre os conceitos de poder e justiça, replicando discursos do não tão antigo "coronelismo".

De tudo conclui-se que não há um final para tudo o que se disse e para o que se tem a dizer. Convém aqui parafrasear Orlandi quanto à incompletude das coisas. Há sempre que se buscar na memória discursiva o respaldo, mesmo que ideológico, para um discurso quem sabe reformulado e ou repaginado, pois ao se fazer referência à linguagem em específico, pode se afirmar da sua infinitude e incompletude como principal característica. No âmbito da dialética entre sujeito e discurso, sentidos da subjetividade vão se formando. Nunca estão prontos e acabados, num trabalho contínuo, "seguindo um movimento contínuo, um movimento constante do simbólico e da história”. (ORLANDI, 1999, p. 37).

\section{REFERÊNCIAS}

ALMEIDA, N. A. Presença literária de Eli Brasiliense. Goiânia: UCG, 1985.

ALTHUSSER, L. Ideologia e aparelhos ideológicos do Estado. Lisboa: Presença, 1980.

BRASILIENSE, E. Rio Turuna: romance. Livraria J. Olympio Editora, 1964.

COURTINE, J. J. Análise do discurso político: discurso comunista endereçado aos cristãos. EdUFSCar, 2009.

FOUCAULT, M. Poder e Saber. In: . Estratégia, poder-paber. Organização e seleção de textos de Manoel Barros da Motta. Tradução de Vera Lúcia Avellar Ribeiro. Rio de Janeiro: Forense Universitária, 2003, p. 223- 240.

FOUCAULT, M. A Arqueologia do Saber. Rio de Janeiro: Forense Universitária, 2009.

GODINHO, D. História de Porto Nacional. Porto Nacional, 1988.

GREGOLIN, M. R. V. A análise do discurso: conceitos e aplicações. ALFA: Revista de Linguística, v. 39, 1995.

GUERRA, V. M. L. Uma reflexão sobre alguns conceitos da Análise do Discurso de linha francesa. Revista Ensaios e Ciência, Anhanguera, v. 7, n. 1, p. 217-232, 2003. 
LEITE, D. M. Alegria e esperança: salve Norte de Goyaz In: Norte de Goyaz, n. 930. Porto Nacional, 01 de junho de 1983.

MAYA, A. L. Reminiscências sociais portuenses. Goiânia, GO: GEV, 2003.

OLIVEIRA, L. A et al. Estudos do discurso: perspectivas teóricas. São Paulo: Parábola, 2013.

ORLANDI, E. P. Análise de discurso: princípios e procedimentos. $5^{\mathrm{a}}$ ed. Campinas, SP: Pontes, 1999.

PALACIN, L. Coronelismo no extremo norte de Goiás: o Padre João e as três revoluções de Boa Vista. São Paulo: Edições Loyola, 1990.

PÊCHEUX, M. Semântica e discurso: uma crítica à afirmação do óbvio. Trad. ORLANDI, Eni Puccinelli. Editora da UNICAMP, 1995.

RODRIGUES, E. S. Terra de Coronéis. Porto Nacional: Alternativa Gráfica e Editora, 2006.

SOARES, T. B. Discurso do Sucesso: sentidos e sujeitos de sucesso no Brasil contemporâneo. Estudos Linguísticos (São Paulo. 1978), v. 45, n. 3, p. 1082-1091, 2016.

\section{Como Referenciar este Artigo, conforme ABNT:}

SOARES, T. B; MAIA, C. T. A Discursividade em Rio Turuna: Uma Análise de Sujeitos e Sentidos da Identidade Goiano-Tocantinense. Rev. FSA, Teresina, v.18, n. 02, art. 13, p. 241-256, fev. 2021.

\begin{tabular}{|l|c|c|}
\hline \multicolumn{1}{|c|}{ Contribuição dos Autores } & $\begin{array}{c}\text { T. B. } \\
\text { Soares }\end{array}$ & C. T. Maia \\
\hline 1) concepção e planejamento. & $\mathrm{X}$ & $\mathrm{X}$ \\
\hline 2) análise e interpretação dos dados. & $\mathrm{X}$ & $\mathrm{X}$ \\
\hline 3) elaboração do rascunho ou na revisão crítica do conteúdo. & $\mathrm{X}$ & $\mathrm{X}$ \\
\hline 4) participação na aprovação da versão final do manuscrito. & $\mathrm{X}$ & $\mathrm{X}$ \\
\hline
\end{tabular}

